\title{
KLASIFIKASI POLA SIDIK JARI MENGGUNAKAN JARINGAN SYARAF TIRUAN BACKPROPAGATION UNTUK ANALISA KARAKTERISTIK SESEORANG
}

\author{
${ }^{[1]}$ Ahmad Fahrudi Setiawan, ${ }^{[2]}$ Alam Katon Agung

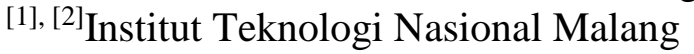

\begin{abstract}
Abstrak : Dewasa ini, banyak bidang ilmu dan penelitian yang telah mengkaji tentang keterkaitan karakteristik seseorang berdasarkan pola sidik jari yang dimilikinya. Pola sidik jari tersebut bersifat unik antara satu sama lain, namun pada dasarnya pola sidik jari dikelompokkan kedalam tiga pola yaitu arch, loop, dan whorl. Pada penelitian ini, penulis membuat aplikasi yang mampu mengenali citra tiga pola sidik jari tersebut untuk keperluan analisa karakteristik anak usia dini. Untuk mengenali citra tiga pola sidik jari tersebut, penulis menggunakan metode jaringan syaraf tiruan backpropagation sebagai sistem yang dapat mengklasifikasi pola-pola sidik jari yang diberikan. Model jaringan syaraf tiruan yang penulis buat yaitu, memiliki 25600 unit pada input layer, 160 unit pada hiden layer, dan 3 unit pada layer output. Citra sidik jari yang digunakan yaitu sebanyak 70 citra pelatihan, dan 30 citra pengujian yang diklasifikasikan menjadi 3 kelas sidik jari yaitu arch, loop, dan whorl. Model jaringan syaraf ini mampu melakukan pengenalan terhadap citra pengujian dengan akurasi $83 \%$.
\end{abstract}

Kata kunci : sidik jari, jaringan syaraf tiruan, backpropagation, klasifikasi, citra

\section{a. Latar Belakang}

\section{PENDAHULUAN}

Pada saat ini, telah banyak penelitian yang mengkaitkan tentang bagaimana karakteristik yang dimiliki seseorang dengan pola sidik jari yang dimiliki orang tersebut. Karakteristik yang dimaksud yaitu meliputi tentang arah kecerdasan, kepribadian, gaya belajar, potensi, dan lain sebagainya. Analisa karakteristik tersebut biasanya ditujukan pada anak usia dini dimana hasil analisa tersebut sangat diperlukan oleh orang tua dalam menentukan metode mendidik dan memberi arahan yang tepat. Pada dasarnya untuk melihat tipe pola sidik jari bisa delakukan dengan mata telanjang. Namun hal itu akan sangat menyulitkan karena keterbatasan kemampuan manusia dalam melihat pola yang berukuran kecil tersebut secara terus menerus dan dalam jumlah banyak.

Berdasarkan latar belakang tersebut maka penulis membuat suatu aplikasi yang mampu mengenali pola sidik jari anak usia dini, yang ditujukan untuk analisis karakteristik setiap murid, pada setiap lembaga PAUD. Sehingga proses pendeteksian pola sidik jari lebih mudah dilakukan dan ketika telah diketahuinya karakteristik sang anak, maka hal tersebut dapat memudahkan pihak lembaga PAUD maupun orang tua dalam menentukan cara atau metode mendidik dan memberi arahan terhadap anak secara tepat sesuai karakteristik anak tersebut. 


\section{b. Rumusan Masalah}

1. Bagaimana cara membuat aplikasi yang mampu mengenali dan mengklasifikasi citra sidik jari?

2. Bagaimana cara membuat aplikasi untuk analisa karakteristik seorang anak berdasarkan tipe pola sidik jari yang dimilikinya?

\section{a. Tinjauan Pustaka}

\section{LANDASAN TEORI}

Seperti yang telah disebutkan (Kumari, 2014), Dermatoglyphics merupakan bidang ilmu yang mempelajari pola sidik jari, telapak tangan dan telapak kaki. pola sidik jari mulai terbentuk pada bulan ke tiga dan terbentuk sempurna pada bulan ke lima. Dimana tujuan dari penelitian tersebut yaitu mencari hubungan antara pola sidik jari dengan berbagai macam kecerdasan berdasarkan bidang ilmu yang diambil oleh partisipan. Sidik jari setiap partisipan tersebut didapat dengan cara cetak tinta 10 jari partisipan tersebut. Partisapan tersebut berasal dari Medical students dan Madical lab technician. Setelah itu pola sidik jari tersebut diidentifikasi dan dianalisa. Pada penelitian tersebut tidak ditemukan perbedaan signifikan. Namun Medical students lebih cenderung gemar mempelajari dan meneliti dari pada Madical lab technician students.

Berdasarkan hasil penilitian dari (Juheri, 2015) yaitu, jaringan syaraf tiruan dapat melakukan identifikasi dengan tingkat keakuratan 85\%. Tingkat keakuratan tersebut dipengaruhi oleh basis data masukkan. Hal tersebut terjadi karena dengan bertambahnya basis data yang digunakan maka variasi ciri sidik jari semakin banyak sehingga menyebabkan ada beberapa ciri pada data tambahan yang masuk menyerupai ciri sidik jari yang lain. Hal ini bisa diatasi dengan menambah ketelitian dari jaringan yaitu menambah besar MSE yang dipakai. Dengan menambah ketelitian jaringan dapat meningkatkan kembali keakuratan jaringan dalam melakukan identifikasi. Namun hal ini juga menimbulkan permasalahan baru yaitu waktu pelatihan jaringan semakin besar.

Sedangkan berdasarkan hasil penelitian dari (Dwiwijayanti, 2014), jaringan syaraf tiruan menggunakan backpropagation berbasis scaled conjugate gradient dapat mengenali pola sidik jari dengan baik. Hasil pelatihan menunjukkan hanya sidik jari sampel 5 dan 8 yang tidak dapat mengenali sidik jari. Hasil pengujian menunjukkan $91 \%$ data sidik mampu dikenali oleh sistem yang sudah dibangun. Sidik jari yang tidak dapat dikenali disebabkan oleh kondisi citra yang dijadikan input memiliki noise akibat jari dalam kondisi kering ataupun berminyak.

\section{b. Keterkaitan Pola Sidik Jari dengan \\ Karakteristik Seseorang}

Setiap anak memiliki karakteristik yang berbeda-beda. Karakteristik tersebut bisa timbul karena faktor eksternal (lingkungan), atau bisa juga berasal dari faktor internal (pewarisan). Yang dimaksud dengan karakteristik berasal dari faktor internal yaitu, karakteristik tersebut didapat dari pewarisan karakteristik orang tuanya yang dibawa melalui gen.

Dalam hal ini, sidik jari merupakan salah satu anggota tubuh manusia, dimana proses terbentuknya pola sidik jari tersebut dipengaruhi oleh gen (Sinta, 2012). Selain itu pola sidik 
jari juga bersifat unik antara satu sama lain, namun pada dasarnya pola sidik jari dikelompokkan kedalam tiga tipe pola yaitu arch, loop, dan whorl (Juheri, 2015), yang ditunjukkan seperti pada Gambar 1. berikut.

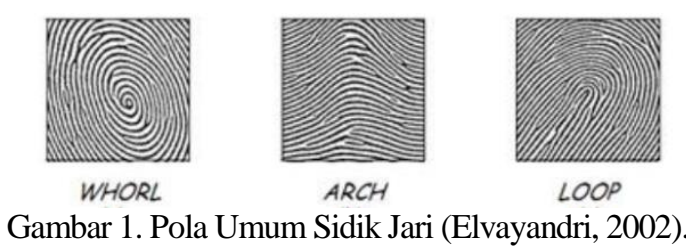

Menurut (Misbach, 2010) setiap sidik jari mencerminkan keunikan setiap individu. Tidak ada kriteria bahwa jenis sidik jari tertentu merupakan jenis sidik jari yang lebih ideal dibandingkan dengan sidik jari yang lain. Pada kenyataannya, secara genetik, antara satu individu dan individu lain tidak ada yang memiliki sidik jari yang sama. Perbedaan individu tersebut dinamakan individual differences berdasarkan bawaan genetik untuk memprediksi prilaku seseorang dalam lingkungan.

Analisis Sidik Jari tersebut bersifat prediksi, dengan tujuan yaitu memberi gambaran mengapa setiap orang berbeda dalam mengekspresikan bakat dan minatnya, gaya belajar, daya tangkap, ketelitian, sampai trait sebagai dasar kepribadian seseorang (Misbach, 2010).

\section{c. Sistem Klasifikasi Citra untuk Pengenalan \\ Citra Pola Sidik Jari}

Kemampuan dari jaringan syaraf tiruan backpropagation dalam mempelajari data kompleks, multi dimensi, dan pemetaan non-linear dari data yang cukup besar sangat baik, sehingga membuatnya menjadi pilihan yang bagus jika digunakan untuk menangani sistem pengenalan pada citra. Dalam model tradisional pengenalan citra, sebuah hand-designed feature extractor mengumpulkan informasi yang relevan dari citra dan mengeliminasi informasi atau variabel yang tidak relevan. Setelah itu, sebuah trainable-classifier mengkategorikan kedalam kelas-kelas. Dalam kasus ini, standar jaringan syaraf tiruan dapat digunakan sebagai trainable-classifier tersebut. (Le Cun, 1995).

Jaringan syaraf tiruan backpropagation dapat diaplikasikan dengan sukses untuk penerapan di dunia nyata. Berdasarkan penelitian sebelumnya (Le Cun, 1990), Jaringan syaraf tiruan tersebut dapat diaplikasikan untuk pengenalan citra tanpa membutuhkan resource yang besar. Pada penelitian tersebut sistem dapat mengenali 2707 citra digit dengan error rate $3.4 \%$.

\section{a. Sampel Citra Sidik Jari}

\section{Metode PEnelitian}

Citra sidik jari diambil menggunakan fingerprint scanner dimana citra yang didapat yaitu berupa citra $R G B$ berukuran 329pixel x 329pixel.

Sebelum dimasukkan kedalam input layer, citra sidik jari tersebut dikonversi menjadi citra grayscele kemudian dikonversi lagi menjadi citra biner. Setelah menjadi citra biner, citra tersebut di resize secara transformasi linier menjadi berukuran 160pixel x 160pixel. 
Dikarenakan pada citra tersebut telah dilakukan transformasi linear, maka citra tersebut memiliki instensitas pixel grayscale lagi. Oleh karena itu citra tersebut harus dinormalisasi dengan max-min normalization dengan skala antara $0-1$. Selanjutnya citra tersebut di reshape menjadi array 1 dimensi sehingga citra tersebut siap digunakan sebagai input jaringan syaraf tiruan.

\section{b. Model Jaringan Syaraf Tiruan}

Jaringan syaraf tiruan ini digunakan untuk mengenali dan mengklasifikasi citra pelatihan, dimana ketika citra pelatihan sudah dapat diklasifikasi dengan sempurna maka akan didapatkan bobot jaringan syaraf tiruan yang optimal. Setelah itu bobot optimal tersebut digunakan untuk mengenaili citra yang diuji.

Model sidik jari yang penulis rancang yaitu memiliki 3 layer. Yang pertama yaitu input layer, memiliki 25600 unit. Yang kedua yaitu 1 hidden layer, memiliki 160 unit dengan fungsi aktivasi sigmoid. Dan output layer, memiliki 3 unit dengan fungsi aktivasi softmax.

Metode propagasi yang digunakan yaitu gradient descent dengan learning rate sebesar 0.5, dan iterasi pelatihan yang dilakukan yaitu sebanyak 1000 kali.

\section{c. Antar Muka Sistem}

Sistem pengenalan citra tersebut diterapkan dalam bentuk aplikasi website. Citra idik jari yang akan dianalisa, harus diunggah pada website tersebut. Sebelum diunggahnya sidik jari tersebut, operator harus menuliskan nama pemilik sidik jari tersebut dan nama kelompok untuk mengelompokkan nama-nama yang telah diunggah tersebut.

Pengisian nama kelompok harus mengisi dua kolom yaitu nama kelompok dan lokasi seperti pada Gambar 2. berikut.

\section{Add Club}

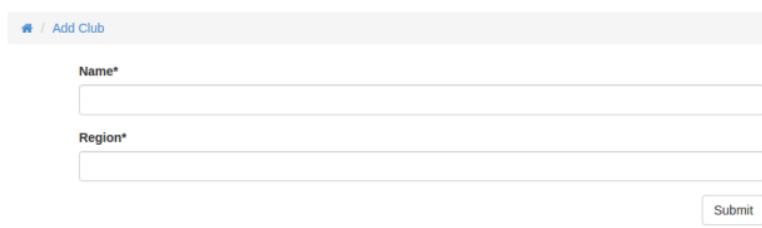

Gambar 2. Memasukkan nama kelompok

Setelah itu yaitu memasukkan nama pemilik sidik jari yang akan diunggah pada aplikasi tersebut seperti pada Gambar 3. berikut.

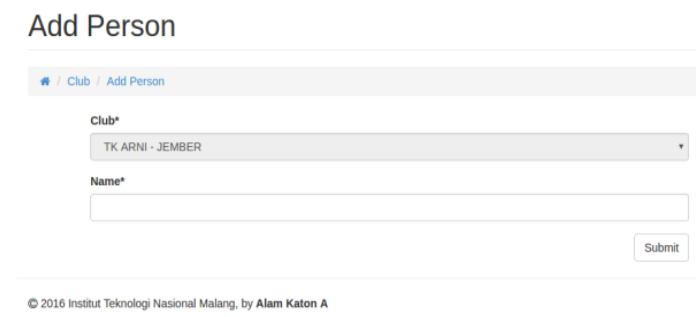

Gambar 3. Memasukkan nama pemilik sidik jari 
Setelah mengisikan nama pemilik sidik jarinya beserta nama kelompoknya, maka akan tersedia form unggah sidik jari beserta form untuk hasil analisanya seperti pada Gambar 4. berikut.

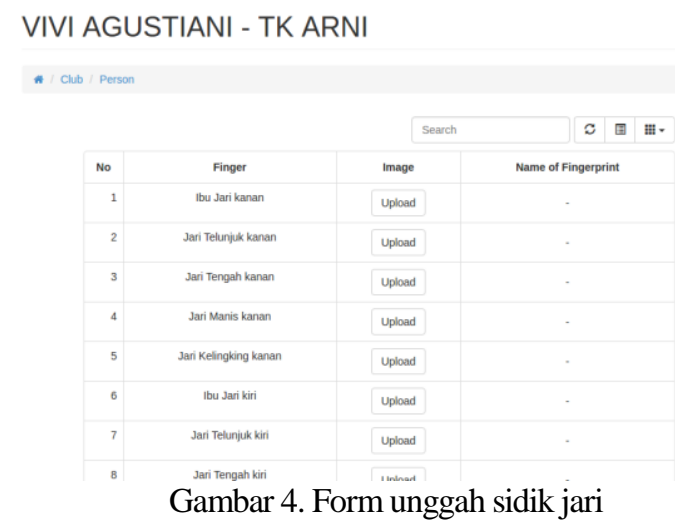

\section{HASIL DAN PEMBAHASAN}

Sampel citra yan digunakan pada sistem ini yaitu sebanyak 100 citra. Citra tersebut dikelompokkan menjadi 2 yaitu citra untuk pelatihan sebanyak 70 citra dan pengujian sebanyak 30 citra. Citra pengujian terdiri dari. Citra pelatihan terdiri dari 5 citra berpola whorl, 23, citra berpola loop, dan 2 citra berpola arch.

Setelah sidik jari diunggah, maka akan tampil nama pola sidik jari yang berhasil dikenali tersebut seprti pada Gambar 5. Berikut.

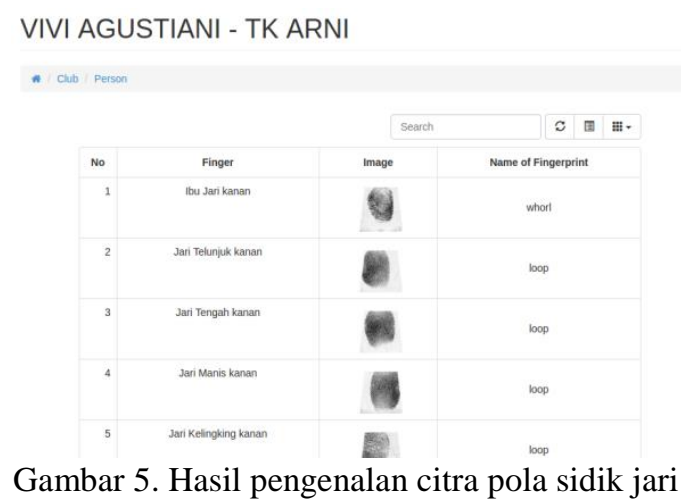

Model jaringan syaraf tiruan tersebut mampu mengenali citra pelatihan dengan prosentase $100 \%$ dan mampu mengenali citra pengujian denga prosentase $83 \%$. Dalam pengujian akurasi untuk mengenali citra berpola whorl sebesar $60 \%$, citra berpola loop sebesar $91 \%$, dan citra berpola arch sebesar $50 \%$.

\section{a. Kesimpulan}

\section{SIMPULAN}

1. Dari model jaringan syaraf tiruan yang digunakan, jaringan syaraf tiruan tersebut dapat mengenali pola citra sidik jari dengan tingkat akurasi $83 \%$. 
2. Jaringan syaraf tiruan tersebut masih belum sepenuhnya bisa mengenali citra sidik jari, dikarenakan citra pelatihan berpola whorl dan loop berjumlah sedikit jika dibandingkan dengan citra pelatihan berpola loop.

b. Saran

1. Agar bisa mencapai akurasi yang lebih tinggi, maka pada model jaringan syaraf tiruan masih bisa ditambahkan jumlah hidden layer ataupun jumlah unit pada hidden layer tersebut dan juga harus disertai perangkat komputasi yang memadai.

2. Citra input jaringan syaraf tiruan tersebut bisa diolah lebih baik lagi agar menghasilkan hasil yang lebih optimal dengan cara mereduksi dimensi menggunakan metode PCA, sehingga citra tersebut bisa lebih cepat diolah.

\section{DAFTAR PUSTAKA}

Dwijayanti, S., Kurniasari, P. 2014. Pengenalan Sidik Jari Menggunakan Jaringan Syaraf Tiruan Berbasis Scaled Conjugate Gradient. Jurnal Mikrotiga, 1(2), 3742 .

Elvayandri. 2002. Sistem Keamanan Akses Menggunakan Pola Sidik Jari Berbasis Jaringan Syaraf Tiruan. Bandung: Institut Teknologi Bandung.

Juheri, A, S. 2015. Identifikasi Pola Sidik Jari Berbasis Transformasi Wavelet dan Jaringan Syaraf Tiruan Propagasi Balik. Universitas Negeri Semarang. Unnes Physics Journal. 4 (1)

Kumari, K., et al, 2014. Dermatoglyphics and Its Relation to Intelligence Levels of Young Students. IOSR Journal of Dental and Medical Sciences, Vol. 13, Issue 5, Ver. II

Le Cun, Y., et al. 1990. Handwritten Digit Recognition with a Back-Propagation Network. Morgan Kaufmann, San Mateo.

LeCun, Y., et al 1995. Learning algorithms for classification: A comparison on handwritten digit recognition. Neural networks: the statistical mechanics perspective, 261, 276.

Le Cun, Y., \& Bengio, Y. 1995. Convolutional networks for images, speech, and time series. The handbook of brain theory and neural networks, 3361(10).

Misbach, I. H. (2010). Dahsyatnya Sidik Jari. ___ _ VisiMedia.

Sinta, H. 2012. Identifikasi tipe Pola Sidik Jari untuk Memprediksi Karakteristik Orang Berbasis Pengolahan Citra Digital. Bandung: Universitas Telkom 